\title{
Lacrimal stenting versus three-snip punctoplasty for treatment of punctal stenosis or occlusion: An open- label, randomized clinical trial
}

\author{
Haitham Rashdan ${ }^{1}$, Ali Mahmoud Ismail ${ }^{1}$, Mohammed Ezz-Eldawla ${ }^{1}$ and Mohammed Iqbal ${ }^{1}$ \\ ${ }^{1}$ Department of Ophthalmology, Faculty of Medicine, Sohag University, Sohag, Egypt
}

\begin{abstract}
Background: To compare the short-term anatomical and functional outcomes of, as well as patient satisfaction with, lacrimal stenting and three-snip punctoplasty for the treatment of punctal stenosis or occlusion.

Methods: In this open-label, randomized clinical trial, we included 50 eyes of 30 patients diagnosed with punctal stenosis or occlusion. They were randomly allocated to two groups of 25 eyes each, using central telephone randomization. Group A underwent a lacrimal stenting procedure and was subdivided into two subgroups: Group A1 (13 eyes) received polyvinylpyrrolidone-coated perforated punctal plugs, and Group A2 (12 eyes) received closed intubation using a bicanalicular silicon tube. Group B included 25 eyes that underwent threesnip punctoplasty. All eyes were examined after 1 day, 1 week, 1 month, 3 months, and 6 months. Postoperative anatomical success assessing the punctum size, functional success using the fluorescein disappearance test, and patient satisfaction based on epiphora scoring were recorded.

Results: Both study groups were comparable in terms of sex and age distribution. Compared to Group B, Group A had a significantly larger punctum size at one, three, and 6-month postoperatively $(P=0.009,0.01$, and 0.02 , respectively). The difference in FDT results was significant between the two groups at all follow-up visits $(P=0.008,0.0001,0.003$, and 0.002 , at postoperative one week, one-months, three-month, and six-month, respectively). Likewise, patient satisfaction was significantly different between both groups at all follow-up visits $(P=0.007,0.001,0.005$, and 0.002 , at postoperative one week, one-months, three-month, and six-month, respectively).

Conclusions: Lacrimal stenting is an effective method for the treatment of punctal stenosis or occlusion. Overall, the FDT results and patient satisfaction outcomes were significantly better.

\section{KEYWORDS}

punctal occlusion, punctal stenosis, epiphora, lacrimal stenting, closed intubation, bicanalicular silicon tube, perforated punctal plugs, three-snip punctoplasty, 3-snip punctoplasty
\end{abstract}

\section{INTRODUCTION}

Epiphora is one of the most frequent complaints encountered by ophthalmologists and has a wide range of differential diagnoses. Patients complaining of epiphora usually present with watery eyes, burning sensation, and eye discomfort. Upper or lower tear-drainage stenosis is one etiological factor of epiphora [1].

The lower punctum is usually located $0.5-1 \mathrm{~mm}$ lateral to the upper punctum on top of the lacrimal papilla,

Correspondence: Mohammed Iqbal, MD PhD, Assistant Professor. Department of Ophthalmology, Faculty of Medicine, Sohag University Sohag, Egypt. E-mail:dr_m_iqbal@yahoo.com. ORCIDiD: https://orcid.org/0000-0002-7954-1277

How to cite this article: Rashdan H, Ismail AM, Ezz-Eldawla M, Iqbal M. Lacrimal stenting versus three-snip punctoplasty for treatment of punctal stenosis or occlusion: An open-label, randomized clinical trial. Med Hypothesis Discov Innov Ophthalmol. 2021 Spring; 10(1): 24-31. https://doi.org/10.51329/mehdiophthal1418

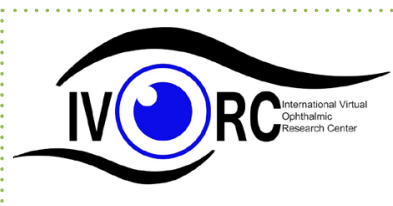

Copyright (C) Author(s). This is an open-access article distributed under the terms of the Creative Commons Attribution-NonCommercial 4.0 International License (http://creativecommons.org/licenses/by-nc/4.0/) which permits copy and redistribute the material just in noncommercial usages, provided the original work is properly cited. (c) (i) \$ 
with a surrounding fibrous ring [2]. Punctal stenosis can be congenital or acquired, with a broad spectrum of etiologies that include trauma; dry eye disease; inflammatory diseases, such as blepharitis; lid margin malposition, mainly ectropion; and age-related changes. It can also develop secondary to radiotherapy or use of topical eye drops, such as antiglaucoma medications [2, 3]. Diagnostic procedures include slit-lamp examination to assess the size and location of the punctum, and examination of the lid margin and conjunctiva for chronic diseases, such as blepharitis or lid margin malposition. In addition, the fluorescein dye disappearance test (FDT) shows delayed dye disappearance in cases of punctal stenosis. The inability to introduce a 26-gauge lacrimal cannula without dilation is also a diagnostic test for punctual stenosis $[4,5]$.

At present, surgeons mostly treat punctal stenosis using punctoplasty (one-, two-, or three-snip punctoplasty) or combined punctal dilation with mitomycin $\mathrm{C}$ application. Furthermore, stenting procedures are becoming more popular and should be preceded by punctal dilation, followed by placement of Mini Monoka stents. In this context, the use of perforated punctal plugs is promising [6-8]. The most common cause of treatment failure involves epiphora recurrence due to restenosis or fibrosis. Other complications include plug extrusion and granuloma formation [9].

The aim of this open-label, randomized clinical trial was to compare the short-term anatomical and functional outcomes of, as well as the patient satisfaction with, lacrimal stenting and punctoplasty for the treatment of punctal stenosis or occlusion.

\section{METHODS}

This open-label, randomized clinical trial received institutional review board (IRB) approval from the Faculty of Medicine, Sohag University, Egypt, before conducting the study. This clinical trial was registered at the Pan African Clinical Trial Registry (PACTR; registration number PACTR201801002952201) and was conducted in accordance with the tenets of the Declaration of Helsinki. All participants provided informed consent after receiving an explanation of the study procedures.

The primary outcome was the patency of the punctum 6 months after the primary surgery. Secondary outcomes included functional success and patient satisfaction based on epiphora scoring at 6-months postoperatively.

Fifty eyes of 30 patients with epiphora, who were diagnosed with punctal stenosis or occlusion and who underwent surgical intervention at Sohag university hospital, between October 2016 and April 2018, were included. The preoperative evaluation included recording a detailed medical and ocular history, including drug history (topical or systemic medications), medical or surgical history, demographics, main symptoms, and onset of epiphora. All participants underwent ophthalmological evaluation, including a detailed slit-lamp examination (SL-3 slit-lamp, ChongQing SunKingdom Medical Instrument Co. Ltd, China), to detect any associated ocular pathology, and to determine the degree of punctal occlusion. Furthermore, syringing and probing were conducted to exclude any associated lacrimal pathway obstruction. Preoperative punctal stenosis was graded using the Kashkouli et al. [1] grading scheme; grades 0-5, defined as no punctum or atresia; papilla covered with a membrane or fibrosis and difficult to recognize; punctum recognizable but smaller than normal; normal; small slit $(<2 \mathrm{~mm})$; and large slit $(\geq 2 \mathrm{~mm})$, respectively. Patients with other lacrimal drainage system pathologies, such as canalicular or nasolacrimal duct obstruction, were excluded.

Participants were randomly assigned to Groups A and B (Figure 1), using central telephone randomization. Group A included 25 eyes Figure, which were further randomly subdivided into subgroups A1 and A2. Eyes in Subgroup A1 (13 eyes) were subjected to lacrimal stenting by insertion of perforated punctal plugs (FCI Ophthalmics Company, Paris, France) (Figure 2). These plugs are coated with polyvinylpyrrolidone to have a perfectly smooth surface, and have a slanted collarette to ensure perfect anatomical fit against the eyelid margin. They are preloaded on a sterile, disposable, single-use plug inserter. Eyes in Subgroup A2 (12 eyes) were subjected to lacrimal stenting involving closed intubation of a bicanalicular silicone tube (Eagle Labs, Rancho Cucamonga, CA, USA). Group B included 25 eyes that underwent three-snip punctoplasty.

Twenty patients underwent bilateral surgery, and 10 underwent unilateral surgery at Sohag University Hospital, performed by a single surgeon (A.M.I). The postoperative treatment regimen was similar for all participants, including 0.5\% moxifloxacin ophthalmic solution (VIGAMOX, Alcon Laboratories, Inc., Fort Worth, TX), 1\% topical prednisolone acetate (Econopred Plus, Alcon Laboratories, Inc.), and lubricating eye drops (Systane Ultra, Alcon Laboratories, Inc.). Additionally, aceclofenac $100 \mathrm{mg}$ tablets twice daily (Bristol-Myers Squibb, BMS, NY, USA) was used for adults, and ibuprofen syrup (Brufen 600, Abbott Laboratories, Abbott Park, IL, USA) twice daily was used in children, for 1 week. Moreover, cefadroxil (Smithkline Beecham Egypt, LLC, Cairo, Egypt; $500 \mathrm{mg}$ tablet for adults and $250 \mathrm{mg}$ for children) was used twice daily. 
Patients were examined on the first postoperative day, and postoperative visits were then scheduled at 1 week, 1 month, 3 months, and 6 months. Recurrence of epiphora and the degree of patient satisfaction based on epiphora scoring were recorded at each follow-up visit. At follow-up visits, epiphora was scored using a combination of the Munk score [10] and the epiphora score described by Malet et al. [11]: score 0 (no tearing), score 1 (transient tearing outside in windy weather), score 2 (constant tearing, sometimes requiring wiping), and score 3 (constant tearing, requiring wiping).

Slit-lamp examination was performed, and the patency of the punctum was checked postoperatively. We graded the postoperative punctal patency as follows: grade 0 was assigned if the punctum was difficult to recognize with the punctal dilator or was totally covered with a membrane or fibrosis; grade 1 was assigned if the punctum was smaller than the normal size but was recognizable and punctal dilation was required; and grade 2 was assigned if the punctum was open and no interventions were required [1]. Subsequently, the FDT was performed to assess the postoperative functional success by instillation of a drop of $2 \%$ fluorescein. Three and 5 minutes later, the dye remaining in the tear meniscus was assessed and graded as Grade 1, Grade 2, and Grade 3 if the dye disappeared in $<3 \mathrm{~min}$, in 3-5 min, and in $>5 \mathrm{~min}$, respectively [5]. Furthermore, on slit-lamp examination at each follow-up visit, we recorded the tear meniscus height, presence of congested conjunctival blood vessels, and lower lid skin maceration, if present. In Group A1, perforated punctal plugs were removed 3 months after surgery, and in Group A2, the bicanalicular silicon tube was removed after 6 months.

Statistical analysis was performed using SPSS Statistics for Windows (version 16.0; SPSS Inc., Chicago, IL, USA). Statistical analysis was performed by a person who was masked to the intervention arms. The independent $t$-test was used to assess the statistical significance of differences in predetermined parameters between the groups, and a paired-t test was used to assess the statistical significance of differences within the same group. Differences were considered statistically significant if $P<0.05$, and highly significant if $P<0.01$.

\section{RESULTS}

Groups A and B were comparable in terms of sex and age distribution. In Group A, seven patients (41\%) were men and 10 (59\%) were women; in Group B, seven patients (54\%) were men and $6(46 \%)$ were women $(P=$ $0.46)$. The mean \pm standard deviation of age was $34.32 \pm 9.11$ years, and $40.54 \pm 7.66$ years in Groups $A$ and $B$, respectively $(P=0.08)$. Table 1 summarizes the patency of the punctum in all follow-up visits. It was graded as open, stenotic, and closed. During the 1-, 3-, and 6-month follow-up visits, significant differences were found between groups $\mathrm{A}$ and $\mathrm{B}(P=0.030, P=0.002$, and $P=0.002$, respectively).

Table 2 shows a comparison of patients' satisfaction, based on epiphora scoring, between Groups A and B at the follow-up visits. At all follow-up visits, there were statistically significant differences between the two groups ( $P=0.007, P=0.001, P=0.005$, and $P=0.002$, at 1 -week, 1-month, 3-months, and 6-months, respectively).

Table 3 shows the mean external punctal size and outcomes of FDT at all follow-up visits. As shown in Table 3, compared to Group B, Group A had a significantly larger punctum size at 1-, 3-, and 6-months postoperatively $(P=0.009, P=0.010$, and $P=0.020$, respectively). In Group A, FDT was $<5$ min (grade 1 or 2$)$ in 24 eyes at 1 -month, and $<5$ min at 6-months postoperatively in 20 eyes. In Group B, after 6 months, 12 eyes showed some degree of stenosis, with FDT $>5$ min and in 13 eyes FDT was $<5$ min. As shown in Table 3, the difference in FDT results was significant between the two groups at all follow-up visits $(P=0.008,0.0001,0.003$, and 0.002 , at 1-week, 1-month, 3-months, and 6-months, respectively).

In terms of postoperative complications, $36 \%$ of the eyes in Group A showed some degree of stenosis, while stenosis was found in $48 \%$ of the eyes in Group B by 6-months postoperatively. The punctum was occluded in only one eye in Group B. In Group A1, loss of perforated punctal plugs was found in two eyes, and partial extrusion of perforated punctal plugs was found in one eye. In Group A2, lacrimal tube prolapse was found in one eye and cheese wiring was found in another eye. No eyes in Group B showed canalicular injury or lacrimal pump failure.

\section{DISCUSSION}

Our study demonstrated the superiority of lacrimal stenting procedures over three-snip punctoplasty. Furthermore, closed lacrimal intubation with a silicon tube yielded statistically significantly better postoperative improvements than perforated punctal plug insertion, including more effective punctal patency, greater external punctum size, and higher patient satisfaction. This study found that closed lacrimal intubation was the best procedure, followed by insertion of perforated punctal plugs and then three-snip punctoplasty. 


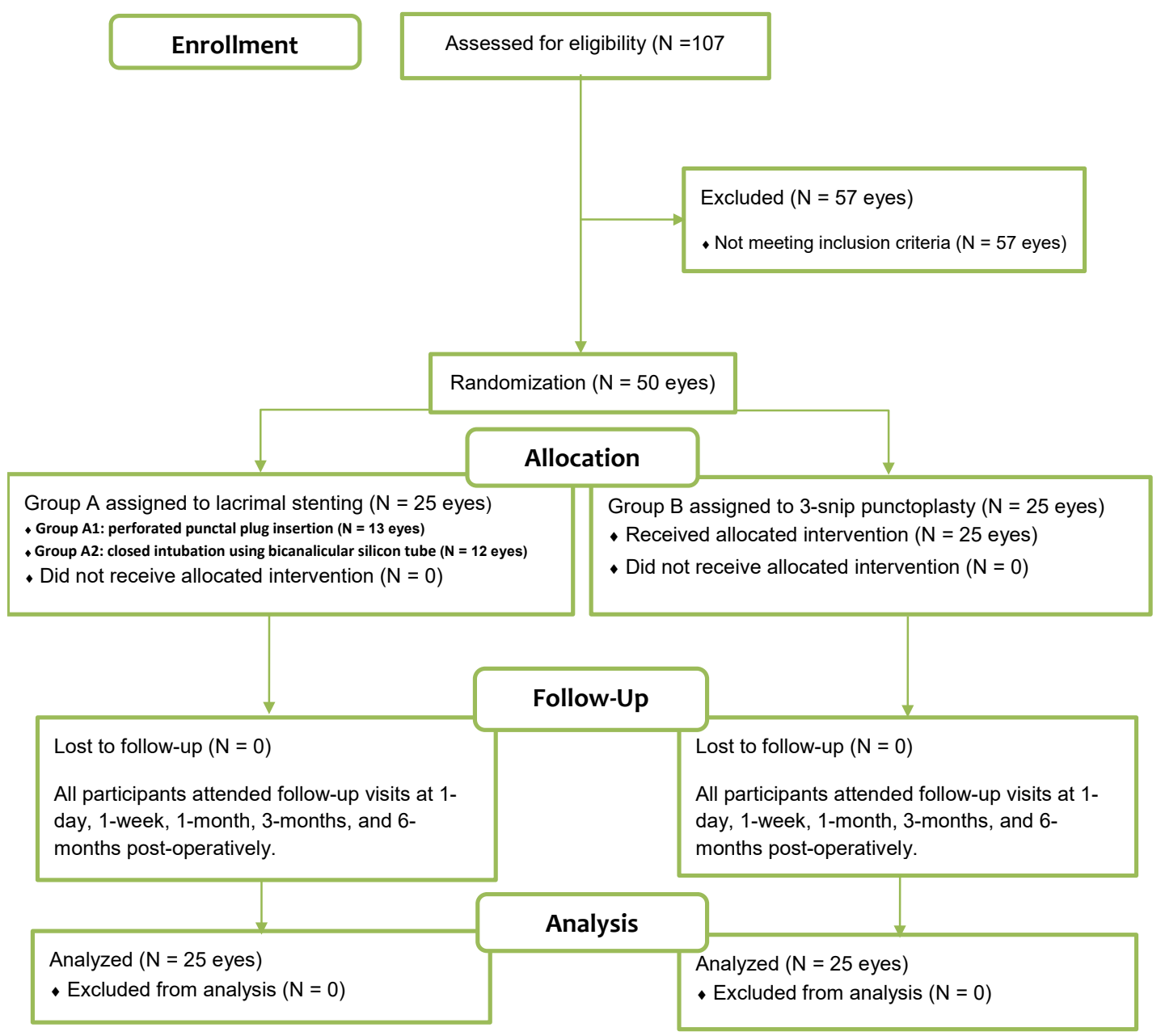

Figure 1. Patient allocation to Group A (lacrimal stenting) or Group B (three-snip punctoplasty).

In a study by Shahid et al. [12] on the outcomes of punctoplasty, the functional and anatomical success rates for punctoplasty surgery were $64 \%$ and $91 \%$, respectively. The patient satisfaction rate was $71 \%$. Anatomical success was comparable between two-snip and three-snip punctoplasty [12]. On the other hand, our study recorded a lower patient satisfaction rate with no tearing or sometimes tearing, which was $64 \%$ and $52 \%$ at 3 - and 6 -months postoperatively, respectively.

Punctum and canalicular stent insertion was introduced to improve the success rate of epiphora or punctal stenosis treatment. It has the advantage that it can treat both punctal and canalicular stenosis simultaneously, which is important, as up to $45 \%$ of punctal stenosis cases are associated with canalicular stenosis. Stent insertion nullifies the need for a snip procedure, thus reducing the risk of fibrosis and restenosis [13]. Hussain et al. found improvement in epiphora in $82 \%$ of 77 eyes at 6 weeks in patients who underwent punctal dilation with Mini Monoka tube insertion, without snip procedures. However, they reported premature stent loss in three patients and stent migration in one patient at the 6-week follow-up [14]. Our study demonstrated the superiority of lacrimal stenting procedures over three-snip punctoplasty with significantly better short-term anatomical and functional outcomes, as well as patient satisfaction.

In acquired punctal stenosis of 44 eyes managed by inserting a perforated punctal plug, the success rate for the improvement of epiphora was $84.1 \%$ (37 of 44 eyes) [15]. Moreover, the success rate reported by Chang et al. [16] was $85 \%$ in a series of 20 eyes. In our study, perforated punctal plugs coated with polyvinylpyrrolidone were used. Follow-up of patients at 3 months after the insertion of the perforated punctal plugs showed that $80 \%$ 
(A)

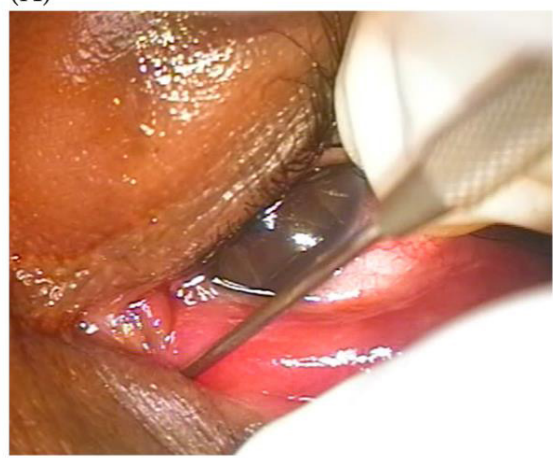

(C)

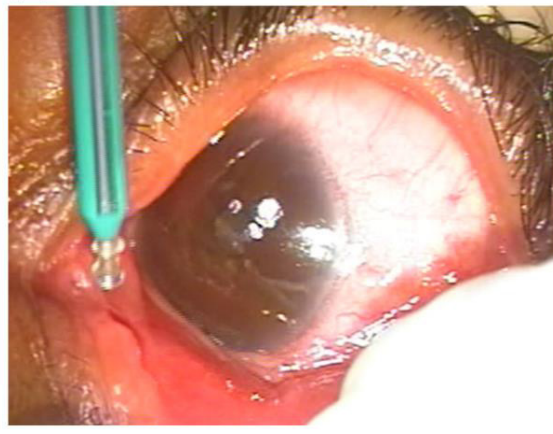

(B)

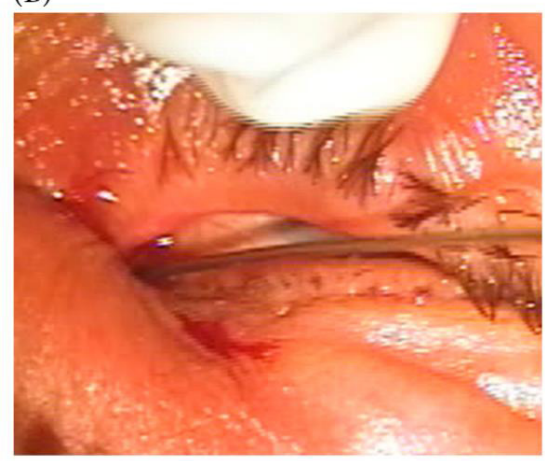

(D)

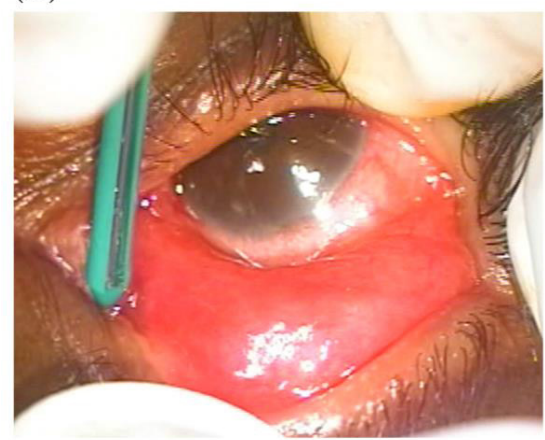

Figure 2. Stepwise approach for perforated punctal plug insertion: (A) Dilation of the lower punctum with a punctal dilator. (B) Probing of the lacrimal passages. (C) and (D) Insertion of perforated punctal plug into the lower punctum.

Table 1. Comparing patency of punctum between Group A (lacrimal stenting procedure) versus Group B (three-snip punctoplasty), and between two subgroups in Group A (A1: perforated punctal plug; A2: closed intubation using bicanalicular silicon tube)

\begin{tabular}{|c|c|c|c|c|c|c|c|c|c|c|c|}
\hline & \multicolumn{6}{|c|}{ Group A } & \multicolumn{3}{|c|}{ Group B } & \multirow[t]{2}{*}{$P$-value ${ }^{1}$} & \multirow[t]{2}{*}{$P$-value ${ }^{2}$} \\
\hline & \multicolumn{3}{|c|}{ Group A1 } & \multicolumn{3}{|c|}{ Group A2 } & & & & & \\
\hline Punctum Status & $\begin{array}{l}\text { Open } \\
\text { n (\%) }\end{array}$ & $\begin{array}{l}\text { Stenotic } \\
\text { n (\%) }\end{array}$ & $\begin{array}{l}\text { Closed } \\
\mathbf{n}(\%)\end{array}$ & $\begin{array}{l}\text { Open } \\
\text { n (\%) }\end{array}$ & $\begin{array}{l}\text { Stenotic } \\
\text { n (\%) }\end{array}$ & $\begin{array}{l}\text { Closed } \\
\text { n (\%) }\end{array}$ & $\begin{array}{l}\text { Open } \\
\text { n (\%) }\end{array}$ & $\begin{array}{l}\text { Stenotic } \\
\text { n (\%) }\end{array}$ & $\begin{array}{l}\text { Closed } \\
\text { n (\%) }\end{array}$ & & \\
\hline $1 \mathbf{w}$ & $10(77)$ & $3(23)$ & $0(0)$ & $12(100)$ & $0(0)$ & $0(0)$ & $21(84)$ & $4(16)$ & $0(0)$ & 0.04 & 0.32 \\
\hline $1 \mathrm{~m}$ & $10(77)$ & $3(23)$ & $0(0)$ & $9(75)$ & $3(25)$ & $0(0)$ & $14(56)$ & $10(40)$ & $1(4)$ & 0.80 & 0.030 \\
\hline $3 \mathrm{~m}$ & $7(54)$ & $6(46)$ & $0(0)$ & $9(75)$ & $3(25)$ & $0(0)$ & $12(48)$ & $12(48)$ & $1(4)$ & 0.01 & 0.002 \\
\hline $6 \mathrm{~m}$ & $7(54)$ & $6(46)$ & $0(0)$ & $9(75)$ & $3(25)$ & $0(0)$ & $12(48)$ & $12(48)$ & $1(4)$ & 0.01 & 0.002 \\
\hline
\end{tabular}

Abbreviations: n, number; \%, percentage; w, week; $m$, month. $P$-value ${ }^{1}$ : comparing Group A1 versus Group A2, and $P$-value ${ }^{2}$ : comparing Group A versus B. $P$-value $<0.05$ is shown in bold.

Table 2. Comparison of patient satisfaction, based on epiphora scoring in follow-up visits, between Group A (lacrimal stenting procedure) and Group B (three-snip punctoplasty)

\begin{tabular}{|c|c|c|c|c|c|c|c|c|c|}
\hline Study Group & & & up A & & & & oup B & & $P$-value \\
\hline Epiphora Scoring & $\begin{array}{l}\text { Score 0 } \\
\text { n }(\%)\end{array}$ & $\begin{array}{l}\text { Score 1 } \\
\text { n }(\%)\end{array}$ & $\begin{array}{l}\text { Score } 2 \\
\text { n }(\%)\end{array}$ & $\begin{array}{l}\text { Score } 3 \\
\text { n }(\%)\end{array}$ & $\begin{array}{l}\text { Score 0 } \\
\mathbf{n}(\%)\end{array}$ & $\begin{array}{l}\text { Score } 1 \\
\text { n }(\%)\end{array}$ & $\begin{array}{l}\text { Score } 2 \\
\text { n (\%) }\end{array}$ & $\begin{array}{l}\text { Score } 3 \\
\text { n }(\%)\end{array}$ & \\
\hline $1 \mathrm{w}$ & $13(52)$ & $12(48)$ & $0(0)$ & $0(0)$ & $8(32)$ & $12(48)$ & $5(20)$ & $0(0)$ & 0.007 \\
\hline $1 \mathrm{~m}$ & $15(60)$ & $9(36)$ & $1(4)$ & $0(0)$ & $6(24)$ & $10(40)$ & $9(36)$ & $0(0)$ & 0.001 \\
\hline $3 \mathrm{~m}$ & $11(44)$ & $9(36)$ & $5(20)$ & $0(0)$ & $6(24)$ & $10(40)$ & $8(32)$ & $1(4)$ & 0.005 \\
\hline $6 \mathrm{~m}$ & $12(48)$ & $9(36)$ & $4(16)$ & $0(0)$ & $7(28)$ & $6(24)$ & $11(44)$ & $1(4)$ & 0.002 \\
\hline
\end{tabular}

Abbreviations: $n$, number; \%, percentage; w, week; $m$, month. Note: Score 0, no tearing; Score 1, transient tearing outside in windy weather Score 2, constant tearing, sometimes requiring wiping; Score 3, constant tearing, requiring wiping. Abbreviations: n, number; \%, percentage; w, week; m, month. $P$-value: for comparing Group A versus B ( $P$-value $<0.05$ is shown in bold $)$. 
Table 3. Comparing the external size of the punctum and the FDT in all follow-up visits between Group A(lacrimal stenting procedure) versus Group B (three-snip punctoplasty)

\begin{tabular}{|c|c|c|c|c|c|}
\hline Variable & \multicolumn{2}{|c|}{ Postop visit } & $\begin{array}{l}\text { Group A } \\
\text { Mean } \pm \text { SD }\end{array}$ & $\begin{array}{l}\text { Group B } \\
\text { Mean } \pm \text { SD }\end{array}$ & $P$-value \\
\hline \multirow[t]{4}{*}{ External size of the punctum ( $\mu \mathrm{m})$} & \multicolumn{2}{|l|}{$1 \mathrm{w}$} & $377 \pm 34$ & $357 \pm 54$ & 0.12 \\
\hline & \multicolumn{2}{|l|}{$1 \mathrm{~m}$} & $489 \pm 86$ & $390 \pm 64$ & 0.009 \\
\hline & \multicolumn{2}{|l|}{$3 \mathrm{~m}$} & $463 \pm 91$ & $377 \pm 51$ & 0.01 \\
\hline & \multicolumn{2}{|l|}{$6 \mathrm{~m}$} & $455 \pm 89$ & $365 \pm 47$ & 0.02 \\
\hline \multirow[t]{12}{*}{ FDT, minutes } & \multirow[t]{3}{*}{$1 \mathrm{w}$} & Grade 1, n (\%) & $12(48)$ & $7(28)$ & \multirow[t]{3}{*}{0.008} \\
\hline & & Grade 2, n (\%) & $13(52)$ & $12(48)$ & \\
\hline & & Grade 3, n (\%) & $0(0)$ & $6(24)$ & \\
\hline & \multirow[t]{3}{*}{$1 \mathrm{~m}$} & Grade $1, \mathrm{n}(\%)$ & $15(60)$ & $6(24)$ & \multirow[t]{3}{*}{0.0001} \\
\hline & & Grade $2, \mathrm{n}(\%)$ & $9(36)$ & $10(40)$ & \\
\hline & & Grade 3, n (\%) & $1(4)$ & $9(36)$ & \\
\hline & \multirow[t]{3}{*}{$3 \mathrm{~m}$} & Grade 1, n (\%) & $11(44)$ & $5(20)$ & \multirow[t]{3}{*}{0.003} \\
\hline & & Grade 2, n (\%) & $10(40)$ & $10(40)$ & \\
\hline & & Grade 3, n (\%) & $4(16)$ & $10(40)$ & \\
\hline & \multirow[t]{3}{*}{$6 \mathrm{~m}$} & Grade 1, n (\%) & $13(52)$ & $5(20)$ & \multirow[t]{3}{*}{0.002} \\
\hline & & Grade 2, n (\%) & $7(28)$ & $8(32)$ & \\
\hline & & Grade 3, n (\%) & $5(20)$ & $12(48)$ & \\
\hline
\end{tabular}

Abbreviations: SD, standard deviation; $\mu \mathrm{m}$, micrometer; w, week; m, month; FDT, fluorescein dye disappearance test; n, number; \%, percentage; P-value: for comparing Group A versus B ( $P$-value $<0.05$ is shown in bold). Note: Grade 1, $<3$ min; Grade 2, 3-5 min; Grade 3, $>5$ min.

of patients experienced no tearing or sometimes tearing, and only $20 \%$ continued to complain of tearing. After 6 months, the percentages remained the same. Perforated punctal plug insertion is an easy and rapid procedure that can be performed under local anesthesia, with a high success rate [16]. It also ensures the drainage of tears by a natural method, thus avoiding damage to the lacrimal sphincter and canaliculus. Furthermore, it secures the patency of the lacrimal puncta without consequential bleeding or scarring. We believe that this procedure would help to avoid repeated dilation of the lacrimal puncta, thus shortening the follow-up period. On the other hand, perforated punctal plug insertion is sometimes difficult or leads to laceration [5]. In our study, we encountered difficult insertion in two cases; however, good dilation and probing of the lacrimal passages and using the proper plug size helped to avoid difficult insertion.

In our study, another group of patients underwent closed intubation using a bicanalicular silicone tube for the management of punctal stenosis, which also yielded excellent outcomes. Ideal stents should be inert, flexible, have a soft external surface, be self-retaining, inexpensive, widely accessible, user-friendly, and should not induce mechanical damage to contiguous soft tissues. Silicon tubes have most of the above-mentioned properties [1719]. We used bicanalicular silicon tube insertion in 12 eyes, and removed them after 6 months. We found that $75 \%$ of these cases achieved an open punctum. Seventy-five percent of patients were highly satisfied, with no tearing postoperatively, $8 \%$ were moderately satisfied, although they complained of sometimes tearing, and $17 \%$ had a low degree of satisfaction as they experienced recurrence of epiphora.

The main complications of lacrimal stents include stent prolapse or loss, which may require repositioning or replacement. Direct visualization using nasal endoscopy is possible. Other complications include punctal slitting or cheese wiring caused by excessive bicanalicular stent loop tightening or inferior pulling, punctal or ostium granuloma formation with prolonged intubation, secondary bacterial or fungal infections, and rarely, corneal erosions and infections [20]. We found loss of perforated punctal plugs in two eyes and partial extrusion of perforated punctal plugs in one eye. Moreover, we detected lacrimal tube prolapse in one eye and cheese wiring in another eye. We removed the silicone tube after 6 months. However, the debate about the ideal timing for stent removal still exists. It is generally recommended to remove the stent between 3 and 6 months after placement. Retaining the stent for a longer time may cause granuloma formation or pyogenic infection [21]. In the current study, no such complications were observed related to the lacrimal stents.

According to our results, lacrimal stenting procedures (either closed intubation or perforated punctal plug insertion) seem to be superior to three-snip punctoplasty in terms of anatomical and functional success. At the 1 -week follow-up, the punctum was open in $88 \%$ of cases with lacrimal stenting and in $84 \%$ of cases with threesnip punctoplasty. After 1-month, the punctum was open in $76 \%$ of cases with lacrimal stenting and in $56 \%$ of 
cases with three-snip punctoplasty. After 6 months, the punctum was open in $65 \%$ of cases with lacrimal stenting and in $48 \%$ of cases with three-snip punctoplasty.

Although, we demonstrated the superiority of lacrimal stenting procedures over three-snip punctoplasty in an open-label, randomized clinical trial. However, the main limitation of this trial was the small sample size, as we included only 50 eyes due to cost-related issues. Another limitation was the relatively short follow-up period, which may not confirm the long-term efficacy of lacrimal stenting. We acknowledge that a larger sample size with a longer duration of follow-up could provide more robust and reliable results. Therefore, we would suggest designing future studies to address these limitations.

\section{CONCLUSIONS}

Our results confirmed the efficacy of lacrimal stenting, either closed intubation or perforated plug insertion, for the treatment of punctal stenosis or occlusion, which yielded significantly better anatomical and functional results and patient satisfaction outcomes than three-snip punctoplasty in patients with punctal stenosis or occlusion.

\section{ETHICAL DECLARATIONS}

Ethical approval: This open-label, non-randomized clinical trial received institutional review board approval from the Faculty of Medicine, Sohag University, Egypt, before commencement. All participants provided informed consent after receiving an explanation of the study procedures. This clinical trial was registered at the Pan African Clinical Trial Registry (PACTR; registration number PACTR201801002952201) and was conducted in accordance with the tenets of the Declaration of Helsinki.

Conflict of interests: None.

\section{FUNDING}

None.

\section{ACIKNOWLED GEMENTS}

The authors are grateful to Prof. Gamal Radwan and Prof. Ahmed Mostafa for their great help and support.

\section{REFERENCES}

1. Kashkouli MB, Beigi B, Murthy R, Astbury N. Acquired external punctal stenosis: etiology and associated findings. American Journal of Ophthalmology. 2003;136(6):1079-84. doi: 10.1016/s0002-9394(03)00664-0 pmid: 14644218

2. Soiberman U, Kakizaki H, Selva D, Leibovitch I. Punctal stenosis: definition, diagnosis, and treatment. Clin Ophthalmol. 2012;6:1011-8. doi: 10.2147/OPTH.S31904 pmid: 22848141

3. Bukhari A. Prevalence of punctal stenosis among ophthalmology patients. Middle East Afr J Ophthalmol. 2009;16(2):85-7. doi: 10.4103/0974-9233.53867 pmid: 20142967

4. Singh M, Gautam N, Ahir N, Kaur M. Is the distance from punctum a factor in the anatomical and functional success of canalicular laceration repairs? Indian J Ophthalmol. 2017;65(11):1114-9. doi: 10.4103/ijo.IJO_499_17 pmid: 29133635

5. Ozgur OR, Akcay L, Tutas N, Karadag O. Management of acquired punctal stenosis with perforated punctal plugs. Saudi J Ophthalmol. 2015;29(3):205-9. doi: 10.1016/j.sjopt.2015.04.001 pmid: 26155080

6. Ma'luf RN, Hamush NG, Awwad ST, Noureddin BN. Mitomycin C as adjunct therapy in correcting punctal stenosis. Ophthalmic Plast Reconstr Surg. 2002;18(4):285-8. doi: 10.1097/00002341-200207000-00010 pmid: 12142762

7. Fraser CE, Petrakos P, Lelli GJ, Jr. Adjunctive re-dilation for early cicatrization after punctoplasty. Orbit. 2012;31(5):313-5. doi: 10.3109/01676830.2012.681751 pmid: 22616663

8. Gupta S, Ali MJ, Ali MH, Naik MN. Assessing the outcomes of mini-Monoka stent dilatation for primary punctal stenosis using the lacrimal symptom questionnaire. Indian J Ophthalmol. 2018;66(2):269-71. doi: 10.4103/ijo.IJO_799_17 pmid: 29380772

9. Boldin I, Klein A, Haller-Schober EM, Horwath-Winter J. Long-term follow-up of punctal and proximal canalicular stenoses after silicone punctal plug treatment in dry eye patients. Am J Ophthalmol. 2008;146(6):968-72 e1. doi: 10.1016/j.ajo.2008.06.028 pmid: 18723140

10. Munk PL, Lin DT, Morris DC. Epiphora: treatment by means of dacryocystoplasty with balloon dilation of the nasolacrimal drainage apparatus. Radiology. 1990;177(3):687-90. doi: 10.1148/radiology.177.3.2243969 pmid: 2243969

11. Malet T, Challier B, David N, Bertrand A, George JL. Clinical and scintigraphic comparison of silicone and polyvinylpyrrolidone coated silicone perforated plugs. Br J Ophthalmol. 1998;82(12):1416-9. doi: 10.1136/bjo.82.12.1416 pmid: 9930274

12. Shahid H, Sandhu A, Keenan T, Pearson A. Factors affecting outcome of punctoplasty surgery: a review of 205 cases. Br J Ophthalmol. 2008;92(12):1689-92. doi: 10.1136/bjo.2008.140681 pmid: 18786958

13. Chalvatzis NT, Tzamalis AK, Mavrikakis I, Tsinopoulos I, Dimitrakos S. Self-retaining bicanaliculus stents as an adjunct to 3-snip punctoplasty in management of upper lacrimal duct stenosis: a comparison to standard 3-snip procedure. Ophthalmic Plast Reconstr Surg. 2013;29(2):123-7. doi: 10.1097/IOP.0b013e31827f5a10 pmid: 23392314

14. Hussain RN, Kanani H, McMullan T. Use of mini-monoka stents for punctal/canalicular stenosis. Br J Ophthalmol. 2012;96(5):671-3. doi: 10.1136/bjophthalmol-2011-300670 pmid: 22241928 
15. Konuk O, Urgancioglu B, Unal M. Long-term success rate of perforated punctal plugs in the management of acquired punctal stenosis. Ophthalmic Plast Reconstr Surg. 2008;24(5):399-402. doi: 10.1097/IOP.0b013e318185a9ca pmid: 18806663

16. Chang M, Ahn SE, Baek S. The effect of perforated punctal plugs in the management of acquired punctal stenosis. J Craniofac Surg. 2013;24(5):1628-30. doi: 10.1097/SCS.0b013e318292c68b pmid: 24036740

17. Alsulaiman N, Alsuhaibani AH. Bicanalicular Silicone Intubation for the Management of Punctal Stenosis and Obstruction in Patients With Allergic Conjunctivitis. Ophthalmic Plast Reconstr Surg. 2019;35(5):451-5. doi: 10.1097/iop.0000000000001315 pmid: 30844917

18. Ahmed RA, Azzam SA. Management of acquired punctal stenosis in trachomatous patients using single versus double silicone tube insertion (a pilot study). Kasr Al Ainy Medical Journal. 2016;22(1):1. doi: 10.4103/1687-4625.182551

19. Ullrich K, Malhotra R, Patel BC. Dacryocystorhinostomy. 2021 Feb 25. In: StatPearls [Internet]. Treasure Island (FL): StatPearls Publishing; 2021 Jan-. pmid: 32496731

20. Repka MX, Chandler DL, Holmes JM, Hoover DL, Morse CL, Schloff S, et al. Balloon catheter dilation and nasolacrimal duct intubation for treatment of nasolacrimal duct obstruction after failed probing. Arch Ophthalmol. 2009;127(5):633-9. doi: 10.1001/archophthalmol.2009.66 pmid: 19433712

21. Ali MJ, Psaltis AJ, Ali MH, Wormald PJ. Endoscopic assessment of the dacryocystorhinostomy ostium after powered endoscopic surgery: behaviour beyond 4 weeks. Clin Exp Ophthalmol. 2015;43(2):152-5. doi: 10.1111/ceo.12383 pmid: 24995830 